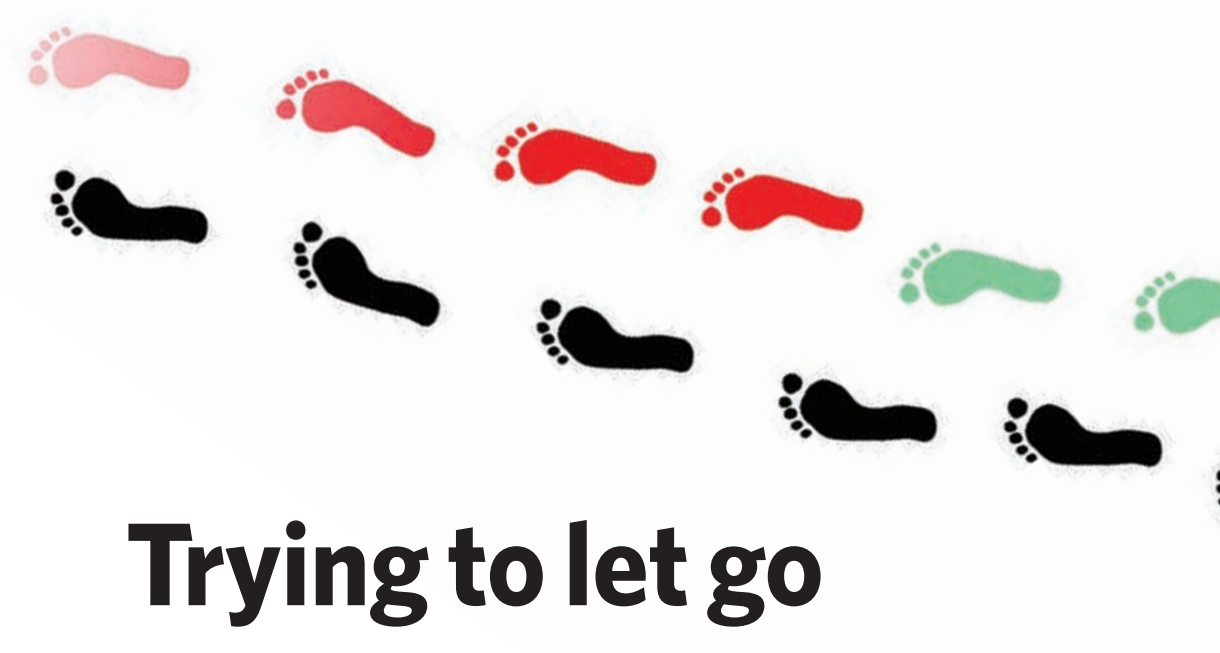

One small step...

\section{Kerstin Hoppenhaus}

When I was born, I was exactly one foot. And I still am - although it wasn't planned that way. When the double-hardened kitchen-knife hit the wooden floor and stuck there, close enough for me to sense the force of its vibrations, they thought it was an accident. Turned out it wasn't.

My first memories are of floating in a gelatinous culture medium carefully kept at $37.1{ }^{\circ} \mathrm{C}$. It took them five months and 17 days to grow me to my full size. Plus another four months of muscle build-up and coordinative training.

I had been raised on a scaffolding of 28 nanofibre bones, a standard human foot - five toes, Egyptian form, first toe longer than the others. My skin is tender, with fine hair; my instep elegantly curved; my entire structure delicate, yet resilient. I'm perfect.

More than that. I am packed with nerve cells and receptors, triplefold beyond natural capacity, prepared to capture the most fleeting bits of information from within and outside myself. A sensitive sole. That's what they call me.

I grew up as an independent entity. Ideal conditions. Solitary training, real-time simulations, the most elaborate embodiment-AI to prepare me for all eventualities out there. I was confident and strong.

So, when we finally were united, it was the first time that I tasted fear.

I should explain.

I am designed to be indistinguishable from the original. Still, there was, of course, for her, a period of absence. Of phantom pain. Of nightmares. Of being torn apart. A cripple.

Her response was immediate and fierce. It came with the first rapid pulses of blood, in the form of hormones, raw and natural. Not just adrenaline, but an entire bouquet of chemicals, rich and manifold, a life away from the purified substances of the lab. Every fibre of me contracted, instantly ready for flight. It was only when the nerve cells kicked in that I encountered something else. An alien will.

You should know: walking is a nearly autonomous process, organized mostly through reflex and design, fast and efficient, with very little input from the higher cognitive centres. Now she was trying to take control, but her signals were rough and inconsistent and my muscles cramped and trembled before I even touched the ground. The cool rush of sedatives saved us both.

It got better over time. She learned to let go.

She had instructions to take us to the beach as often as possible. The sand was supposed to be good for us. And good it was. We started out in the compact wet sand near the water. That was easy. The dynamics of bipedal walking: stabilization and coordination, swing and stance. Coming down, heel first, roll to the ball and on to the toes, then airborne again, sent forward by the mighty muscles of the upper leg. Almost like flying. Dry sand was more difficult, but its warmth and the fine grains massaging my skin easily outweighed the effort. We walked. We ran. We even jumped. I soon learned to melt into the rhythm of her body, a seamless flow of information. Tentative happiness trickling down from the pituitary gland.

Sometimes, when resting, I felt her consciousness visiting me, travelling along the inside of my skin, the smooth surface of my artificial bones, taking stock, vaguely familiar and vast. But mostly we communicated only through the intricate network of our reflex arcs.

Sometimes, in the early stages of sleep, I drifted. Up the sensory nerve tracts, past the spinal cord and the brainstem to the parietal lobe. Her entire body was mapped out there, information from all realms of perception. Eyes and ears and tongue. Dreamy exchanges with my neighbours. Hands, bowels, genitals.
I finally was where I belonged. Her body was whole again, its machinery fully restored. The purpose of my existence.

Until we fell.

I think it was I who stumbled. Some minor obstacle, just above my compensation threshold. I remember getting up, unharmed, and then, suddenly, from all directions, a rise of massive white noise. Rapid signals with no shape, screeching receptors, tightening vessels, thin cold sweat. A few long heartbeats. Then, in one soft instant, she contracted into a single point, somewhere deep inside. All went slack. We crashed to the ground.

Soon, her consciousness returned. Order was restored. Coherence. But nothing went like before. Instead, it got worse with every step. Memories of old injury incessantly seeped into me from hidden places. Traces of the other. The phantom. I am grown from her own cells, part of her own body, but in her mind I was dead. In her mind I was hurting.

Of course I tried to help. I knew what to do. I was made for this. At night, I tried to remap her brain, replace the torn image of the other with my present state. Intact. I presented myself in her dreams. I even tried to move on my own. Lead by example. Prove to her that she was whole again. That her mind was wrong and I was right. But she didn't recognize me.

Instead, she stopped sleeping. Watched me. Kept me away from her with outstretched legs. Tried to pull me off, with both hands, like a boot with a too-narrow shaft. Kicked me against stairs and rocks. Chopped at me with iron blades. Until they tied her up.

Now I am on my own again, somewhere, in a tank. The perfect foot. An experiment abandoned.

Kerstin Hoppenhaus has studied biology and is now a film-maker and science journalist. She lives in Berlin, Germany, and on the web at www.digitalgrip.de. 